\title{
Temperature dependence of some properties of star-branched polymers in confined space. A Monte Carlo study
}

\author{
P.Romiszowski* \\ Department of Chemistry, University of Warsaw, \\ 02-093 Warszawa, Poland
}

Received August 30, 2001

\begin{abstract}
A simulation study of star-branched molecules with 3 arms was performed in a space confined between two parallel repulsive walls, which were at the distance $d$ apart. The simulations were performed for chains on a simple cubic lattice. The chains consisted of $N=49,100$ and 199 beads. During the simulations the solvent quality has been varied by means of changing the segment-segment interactions. Also the thickness of a layer between the walls has been changed. The results show that there is a coil-to-globule transition. The transition temperature does not depend on the confinement. However, the scaling exponents of the radius of gyration of the chains are sensitive to value $d$.
\end{abstract}

Key words: Monte Carlo simulation, confined space, branched polymers, coil-globule transition

PACS: 02.70.Lq, 36.20.Ey, 61.25.Hq, 07.05.Tp

\section{Introduction}

For the recent 20 years, the problem of the properties of polymeric systems that are observed in a special environment has attracted the attention of numerous researchers. The modern technology of polymers as well as their application required the solution of many basic problems connected with the specific geometrical confinement. Many polymeric systems used as composites, microlayers or thin films exhibit quite different properties compared to the melt or solution systems in unrestricted 3D space. The presence of geometrical constraints causes a considerable shrinking of the conformational space of the system. The space confinement most frequently used in literature was a slit [1-9], which served as a tool for investigations of the properties of linear polymers in thin layers, microstructures and finally in biosystems. Moreover, the cylindrical space confining the molecules was applied

*E-mail: prom@chem.uw.edu.pl 
in simulations [10]. Some papers were devoted to the static and dynamic properties of a polymer melt in confinement [11,12]. All mentioned authors have reported the system anisotropy which effected the specific properties of the systems.

The properties of star branched polymers in unrestricted space have recently been studied by many authors. They paid attention to both the static and dynamic properties of the systems under consideration. The star-branch molecules appear to be nice stepping-stone model objects for studying the systems in which the topology of the molecule plays an important role. The simplest star-branched polymers are the molecules with $f=3$ arms of equal length. As it has been shown, such objects sometimes exhibit the properties different from their linear counterparts [13]. The differences were mostly caused by the non-uniform density of stars as well as by the interactions between the arms.

The confinement of the molecule changes the properties of the molecule which does not behave as a free chain - the geometrical obstacles change the configuration space in comparison with the unrestricted conditions. Also, the interactions with the walls confining the object deform the molecule. As a result of these phenomena, one observes considerable effects of the presence of confinement in static and dynamic properties of the system. An interesting result concerning the coil-to-globule transition has recently been presented by Sotta et al. [10] that carried out the simulations of a grafted polymer chain confined in a tube. They found out that the coil-globule transition is continuous. As they showed, the chain structure was a succession of blobs within which the transition took place independently of the overall chain length.

In this study, the influence of temperature (solvent quality) of the system is investigated, especially with respect to the size of the molecules located between the two impenetrable walls. Also, the coil-to-globule transition of the system has been derived from the simulations. The simulations were performed for a series of different separations between the walls in order to see the effect of the size of the slit. On the other hand, the solvent quality was varied as well as the chain length. Here the three different chain lengths (the next one doubled the previous length) were used, which enabled one to obtain the scaling of the system.

\section{The model}

The model system considered in these simulations consisted of a Monte Carlo box with periodic boundary conditions in $x y$ plane. The walls perpendicular to $z$ axis were impenetrable for the chain located between them. The scheme of the system is shown in figure 1. The impenetrable (purely repulsive) walls were separated at a distance $d$, which was varied in a series of simulations. The simulations were started from $d=3$, i.e. the distance between the walls was 3 lattice units, which is the distance large enough to enable all the micromodifications of the chain in 3 dimensions provided that the ergodycity of the system is present. The variation of the distance between the walls $d$ enabled one to study the effect of deformation of the chains in two regimes: first ( $d$ much less than the mean square radius of gyra- 


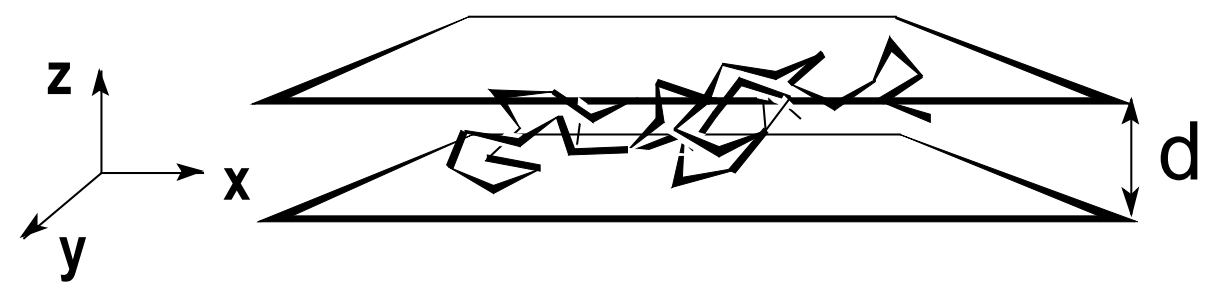

Figure 1. Schematic representation of the chain located between the walls used in the simulations.

tion without any confinement $\left\langle S^{2}\right\rangle_{0}$ in which the chain is highly squeezed, but still all possible micromodifications of the chain segments can be executed; the second regime is at $d$ larger than $\left\langle S^{2}\right\rangle_{0}$, but still the chain "feels" the confinement. The chains were simulated on a simple cubic lattice with excluded volume effect present, which means that the double occupation of the same lattice knot was forbidden. The molecules consisted of $f=3$ arms of equal length $n=17,34$ and 67 emanating from one point, called a branching point. The total number of beads in a molecule was $N=f(n-1)+1$, in this case the chain length was $N=49,100$ and 199 beads, respectively. In order to study the properties of the system along with the change of the solvent quality, a contact potential of the mean force $V=\varepsilon$ has been introduced. The potential has been in effect for the pairs of nonbonded beads separated by a distance of 1 lattice unit; otherwise, for longer distance $V=0$. No other local potentials were present in the system. Since it has been assumed that the attractive forces are present in the system, the interaction parameter $\xi=\varepsilon / k T$ has been negative. The reference state $(\varepsilon=0)$ means that the solvent-segment and segmentsolvent interactions are identical. For $\varepsilon<0$, the segment-segment interactions are more preferable than segment-solvent interactions and one observes gradual changes the of the properties of the system. The changes in $\varepsilon$ mean the changes in solvent quality - the more negative $\varepsilon$, the worse is the solvent quality. On the other hand, the changes in solvent quality can be interpreted as the changes of the temperature $T$ of the system without changing the solvent. In this paper this method will be used, as a measure of the temperature $T^{*}=|k T / \varepsilon|=1 /|\xi|$ is applied.

\section{Results and discussion}

The simulations were started at given $T^{*}$ and $d=3$ from a flat random structure located between the walls. Then, the equilibration run was performed and the simulation was started. During the simulation run, the trajectory was recorded it consisted of 3000 to 5000 snapshots of the system taken in equal time intervals. Having finished the simulation, the distance between the walls was increased and the new procedure was repeated. The last chain conformation served as a starting chain for the new equilibration run and so on. After the series of simulations, the trajectories were analyzed and the data were extracted. It was the aim of this study to examine the coil-to-globule transition in the confined system as well as to obtain the scaling dependencies. 
The initial configuration of a model chain in a given simulation run underwent a series of local micromodifications during which the positions of some beads (segments) were randomly changed. As it has been shown, there exists a set of elementary micromodifications which allows the chain to move to any point in the phase space. These are the following: (i) two-bond chain end motion, (ii) two-bond kink motion, (iii) three-bond kink motion, (iv) three-bond $90^{\circ}$ crankshaft motion, (v) branching point collective, i.e. accompanied by the move of one of the nearest bonded bead, motion. A detailed description of the above elementary motions was given elsewhere [14]. Since the total energy of the system was the sum of all pairwise segment-segment contacts (the contact was assumed when the distance between the non-bonded beads was equal to one lattice unit, i.e. 1), the micromodifications of the chain usually changed the total configurational energy of the molecule along with the changes of a number of contacts between the segments. In the simulation, the number of these contacts has been monitored continuously. The Metropolis sampling was applied in order to efficiently sample the configurational space and to calculate the temperature dependencies of the system. The transition of the system from an "old" to a "new" configuration was effective unconditionally when the number of contacts did not decrease (i.e. the configurational energy remained constant or was increased). If the number of segment-segment contacts decreased during the micromodification, then the probability of the acceptance of such a move was computed according to the relation $P=\exp (-\Delta E / k T$ ) (where $\Delta E$ was the difference between the "new" and "old" conformation) and then the change of the chain conformation was executed with this probability. By performing the series of simulations at a wide range of reduced temperature $T^{*}$ (from $T^{*}=10$ to 1 ) one could examine the properties of the chains both in a good and in a poor solvent regime.

The changes in the solvent quality strongly influence the dimensions of the chains, which are usually characterized by the mean square radius of gyration $\left\langle S^{2}\right\rangle$ - this parameter was calculated for each simulation condition $\left(d\right.$ and $\left.T^{*}\right)$. In order to study the dependence of chain dimensions on the distance between the plates $d$ for different solvent quality, we have plotted the results in figures $2-4$ which are done for different chain lengths. The $x$-axis of these figures represents the ratio $d / 2\left\langle S_{0}^{2}\right\rangle_{T}^{1 / 2}$. The doubled mean square root of the radius of gyration with no confinement present $\left\langle S_{0}^{2}\right\rangle_{T}$ taken at a given temperature $T^{*}$, is roughly equal to the diameter of the coiled macromolecule. Calculating the ratio of this quantity with respect to the distance between the wall, enables one to estimate the proportion between the size of the molecule and $d$, which results in the degree of "squeezing" by the repulsive plates confining the chain. The $y$-axis of the plots is the ratio of the observed value of the mean square radius of gyration to that obtained without the confinement at the given solvent quality (temperature $T^{*}$ of the system). Therefore, we can normalize the effect of the interaction of the chain with the walls independently of the size of the molecule. In fact, the curves obtained for different temperature values of interaction parameter $\xi$ form a family of similar plots. Each of these curves exhibits the minimum which is located close to the abscissa value 1 . However, one can notice that the position of this minimum changes toward the larger values of abscissa 


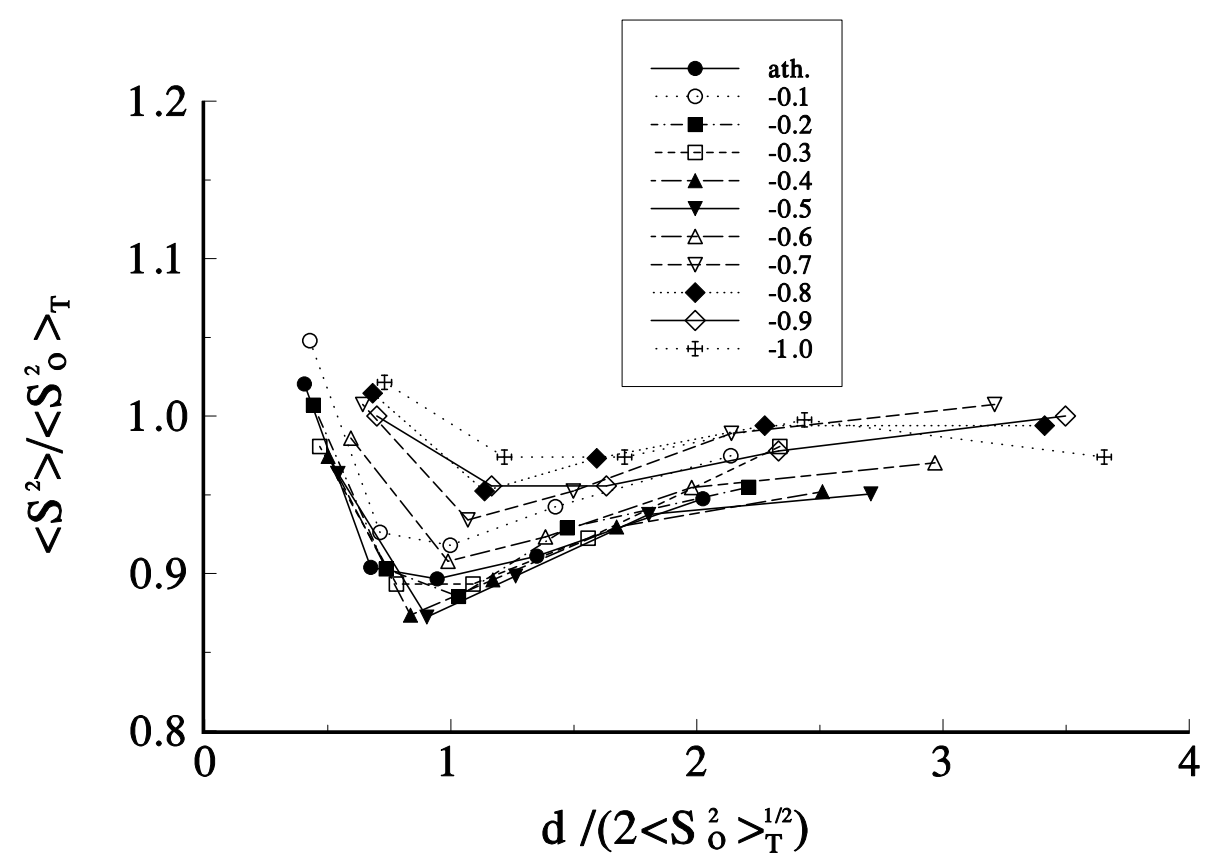

Figure 2. The dependence of the radius of gyration of the chain on the distance between the walls at various solvent conditions (values of interaction parameter $\xi$ are given in the inset) $-N=49$. See text for details.

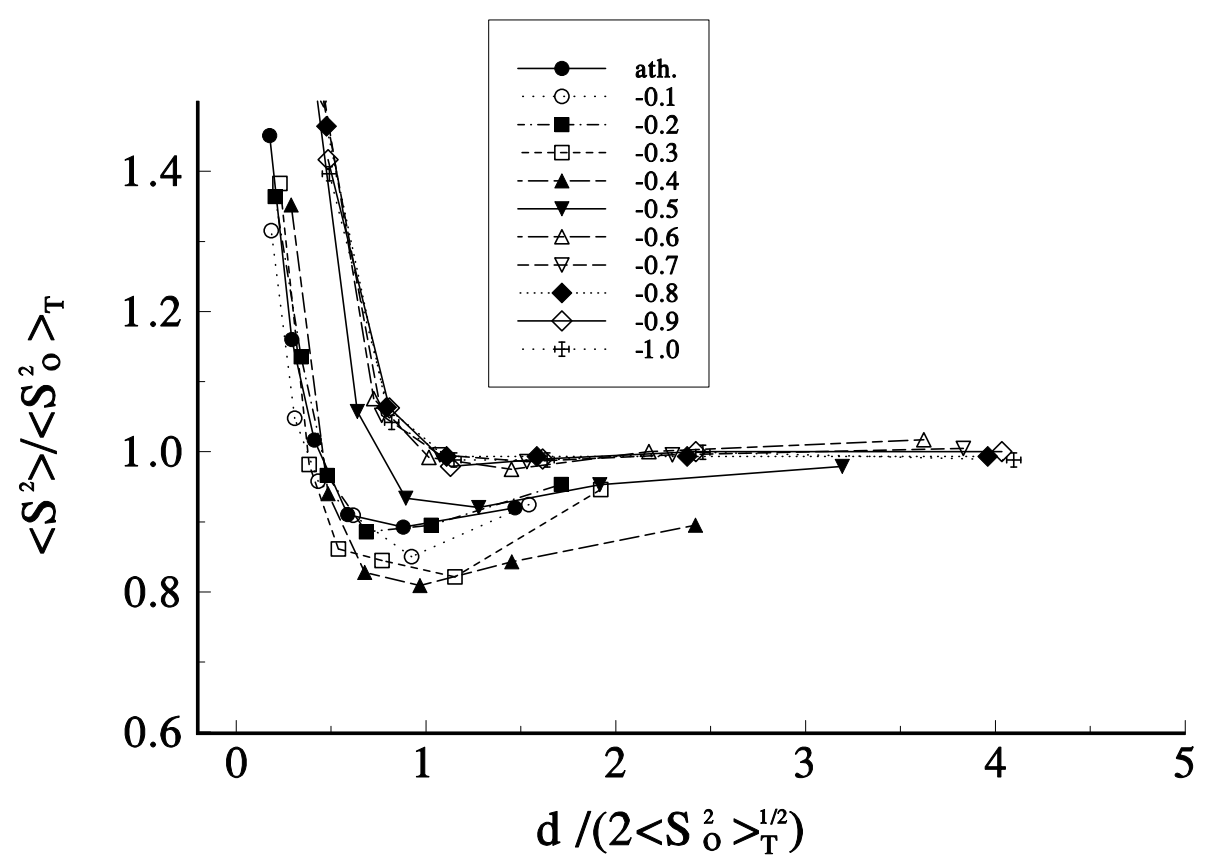

Figure 3. The dependence of the radius of gyration of the chain on the distance between the walls at various solvent conditions (values of interaction parameter $\xi$ are given in the inset) $-N=100$. See text for details. 


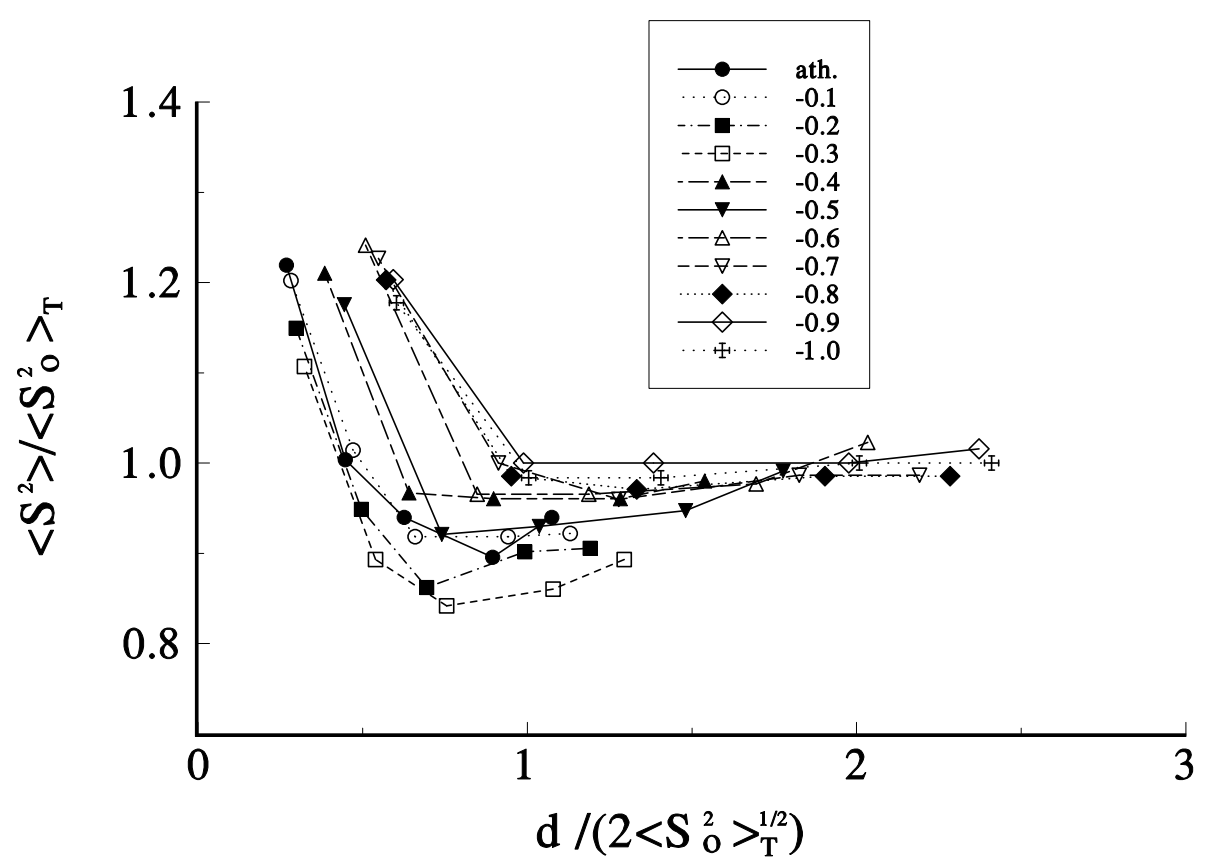

Figure 4. The dependence of the radius of gyration of the chain on the distance between the walls at various solvent conditions (values of interaction parameter $\xi$ are given in the inset) $-N=199$. See text for details.

along with the decrease of $\xi$, which is equivalent to the decrease of $T^{*}$. Also, one can observe that the depth of the minimum on curves is less pronounced as the quality of the solvent worsens. For a bad solvent regime, the minimum vanishes, which is in agreement with the work by Cordeiro et al. [5]

In each figure, the data for an a thermal solution (good solvent regime) are given. The presence of the minimum on each curve has also been observed by other authors. The explanation of this phenomenon can be as follows: as the distance between the walls decreases, the molecule becomes more flat since the $z$-axis of the system is limited by $d$. Therefore, the $z$-component of the radius of gyration decreases. On the other hand, during the "squeezing" process the $x y$-components of $\left\langle S^{2}\right\rangle$ increase. Since $\left\langle S^{2}\right\rangle$ is the sum of these two components, the minimum have to appear on the plot. The location of this minimum in the vicinity of abscissa value 1 is obvious, since at $d$ close to the diameter of the molecule, the walls start to interact considerably with the chain and the evident "squeezing" of the molecule starts as $d$ decreases. As the quality of the solvent worsens, this effect takes place at larger values of $d$. The partially collapsed chain forms a more dense structure and, therefore, it starts to interact with the walls when the distance between the plates is larger than in case of a good solvent.

Since the simulations were made for different values of $T^{*}$, this enabled one to study the collapse of the chain from a coil to globular state. In order to do so, the energy fluctuations during the simulations were calculated, which enabled one to 


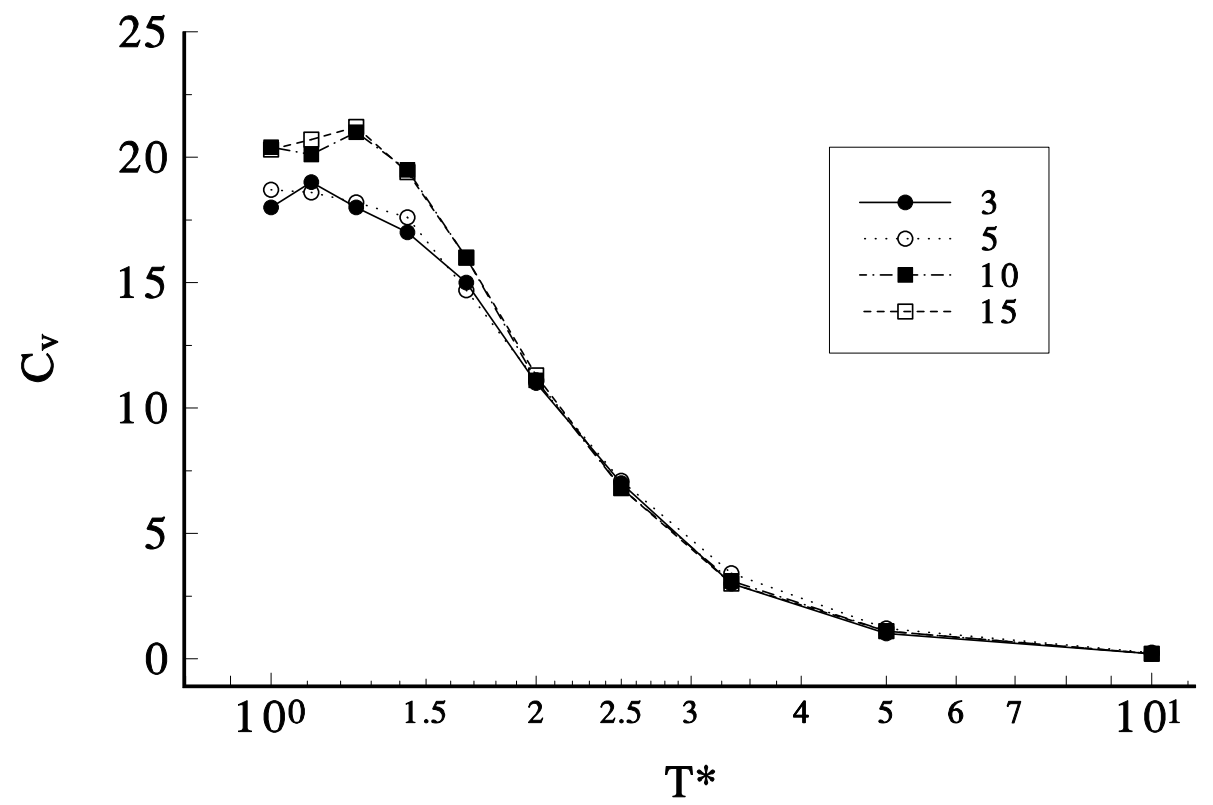

Figure 5. Plots of heat capacity $C_{v}$ as a function of reduced temperature $T^{*}$ for different distances between the walls $-N=49$.

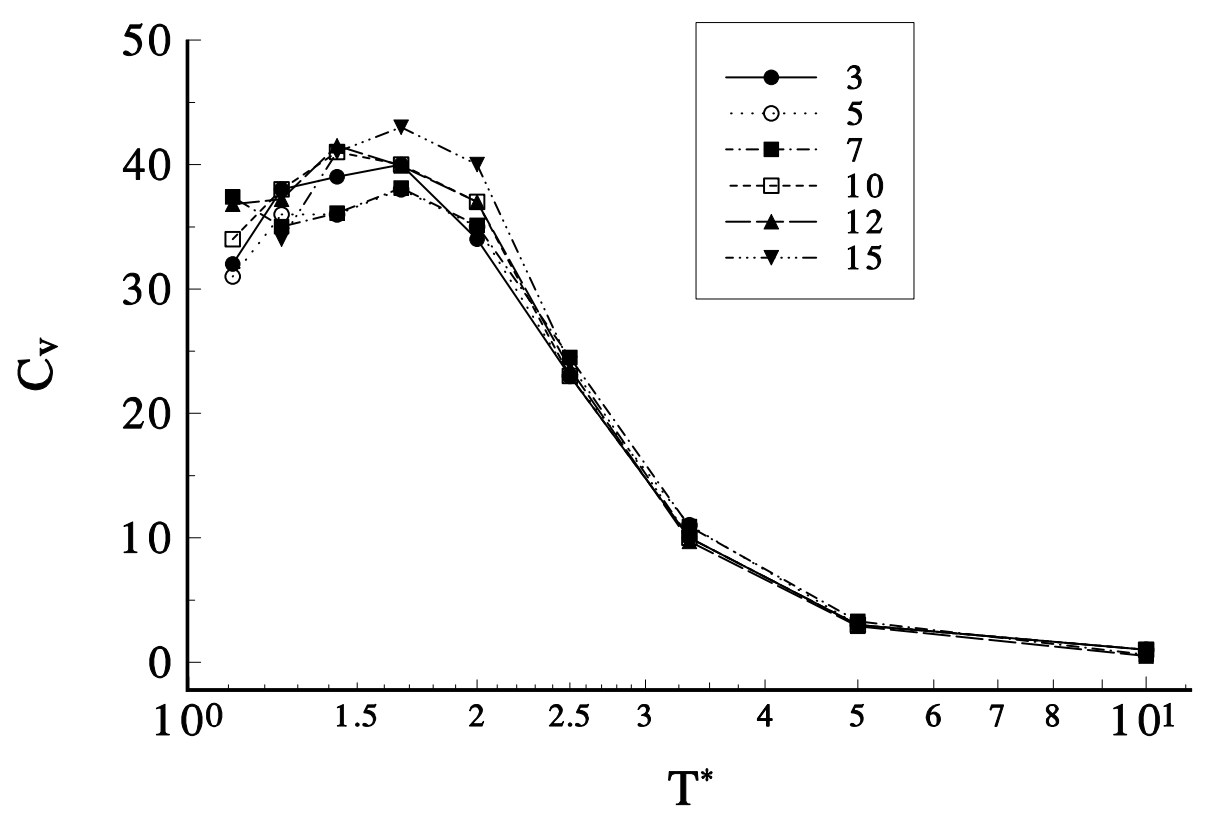

Figure 6. Plots of heat capacity $C_{v}$ as a function of reduced temperature $T^{*}$ for different distances between the walls $-N=100$. 


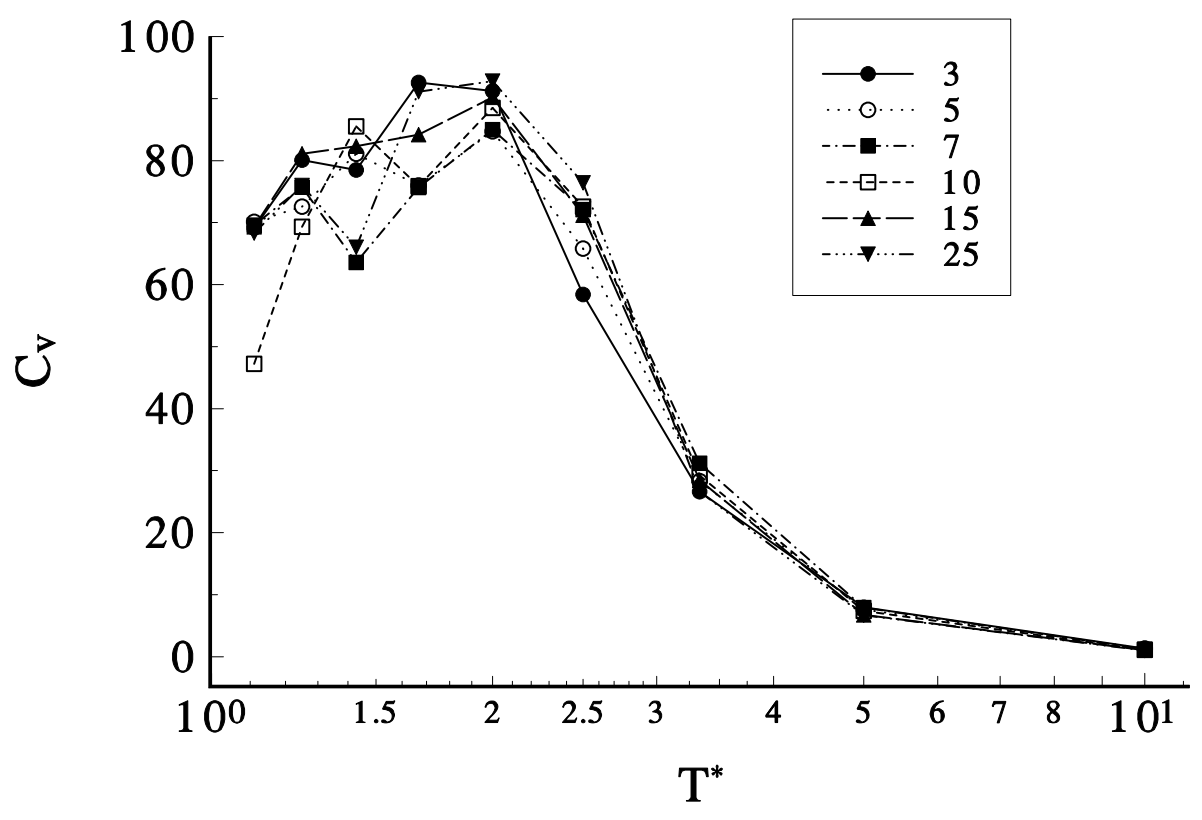

Figure 7. Plots of heat capacity $C_{v}$ as a function of reduced temperature $T^{*}$ for different distances between the walls $-N=199$.

plot the heat capacity $C_{v}$ according to the fluctuation theorem:

$$
C_{v} / k=\left\langle E^{2}\right\rangle-\langle E\rangle^{2},
$$

where $E$ is the total configurational energy of the molecule averaged over the large number $\left(\sim 10^{6}\right)$ of configurations. Plotting $C_{v}$ as a function of the temperature of the system shows whether or not there is a phase transition of the system. In figures $5-7$, the plots of $C_{v}$ against the reduced temperature $T^{*}$ are shown for different values of $d$. Each of the curves exhibits the maximum which signs the position of a coil-toglobule transition temperature. The transition temperature $T_{c}$ estimated from the plots is 1.1, 1.7 and 2.0 for $N=49,100$ and 199, respectively. These values are almost the same as those obtained for star-branched molecules with no confinement (1.0 for $N=49$ and 2.0 for $N=199$ ) [15]. As one can notice, there are no considerable differences in the course of the plots for various values of $d$, which means that even great changes in the environment of the chain does not influence its phase transition behaviour. This effect is interesting because along with the decrease of the slit size $d$ one approaches the $2 \mathrm{D}$ regime. On the other hand, even at the smallest value of $d=3$, all the mechanisms of changing the conformation were present and from the standpoint of the system characteristics, one deals with the objects featuring the same mechanism of conformational changes.

The scaling of dimensions with the number of beads in a molecule gives one the very important information about the expansion of the chain in a solvent - in a good solvent regime the dimensions are proportional to $(N-1)^{\gamma}$ with $\gamma=6 / 5$, at $\Theta$ conditions $\gamma=1$ and for a globular state it reaches the value $2 / 3$. These relations are valid for a linear chain, but also hold in a case if star-branched polymers in a limit of infinite $N[16]$. In this work, scaling relations were extracted for three cases: a good 
Table 1. Values of scaling exponents $\gamma$ for different solvent regimes for small distances between the walls $d$.

\begin{tabular}{|c|c|c|c|c|}
\hline$\xi$ & $d=3$ & $d=5$ & $d=7$ & $d=10$ \\
\hline-0.1 & $1.30 \pm 0.01$ & $1.24 \pm 0.05$ & $1.14 \pm 0.05$ & $1.05 \pm 0.01$ \\
\hline-0.4 & $1.00 \pm 0.02$ & $0.83 \pm 0.03$ & $0.72 \pm 0.07$ & $0.68 \pm 0.06$ \\
\hline-1.0 & $0.78 \pm 0.03$ & $0.59 \pm 0.04$ & $0.57 \pm 0.01$ & $0.55 \pm 0.01$ \\
\hline
\end{tabular}

solvent regime $(\xi=-0.1)$, the vicinity of the coil-to-globule transition temperature $(\xi=-0.4)$ and finally, a bad solvent regime $(\xi=-1.0)$. The scaling exponents of the relation $\left\langle S^{2}\right\rangle \sim(N-1)^{\gamma}$ were calculated for different values of the separations of the plates $d$. The results are given in table 1 .

As one can see, the decrease of the distance between the walls $d$ increases the scaling exponent $\gamma$. At a good solvent regime, the scaling strongly depends on $d$ giving the values much higher than those observed for chains without confinement - this is in agreement with the results of Milchev and Binder [3]. At considerably small values of $d$, the system approaches the $2 \mathrm{D}$ case, for which the scaling exponent $\gamma=3 / 2$ in a good solvent, which is in agreement with the tendency shown in Table 1 (value 1.30). The scaling for the collapsed globule $(\xi=-1)$ is closer to that from the theoretical predictions of value $2 / 3$. Discussing this problem, one should remember that the repulsive effect of the walls introduces a strong anisotropy of the molecule and,thus, the further detailed investigations of the shape of the confined star-branched molecules in a slit would complete the study.

\section{References}

1. Sanat K.K., Vacatello M., Yoon D.Y Off lattice Monte Carlo simulations of polymer melts confined between two plates. // J. Chem. Phys., 1988, vol. 89, p. 5206-5215.

2. van Vliet J.H., ten Brinke G. Orientation and shape of flexible polymers in a slit. // J. Chem. Phys., 1990, vol. 93, p. 1436-1441.

3. Milchev A., Binder K. Dynamics of polymer chains confined in slit-like pores. // J. Phys. II France, 1996, vol. 6, p. 21-31.

4. Milchev A., Binder K. A polymer chain trapped between two parallel repulsive walls: A Monte Carlo test of scaling behaviour. // Eur. Phys. J. B, 1998, vol. 3, p. 477-484.

5. Cordeiro C.E., Molisana M., Thirumalai D. Shape of confined chains. // J. Phys. II France, 1997, vol. 7, p. 433-447.

6. Van Giessen A.E., Szleifer I. Monte Carlo simulations of chain molecules in confined environments. // J. Chem. Phys., 1995, vol. 102, p. 9069-9076.

7. Cifra P., Bleha T. Anisotropy in the dimensional and elastic parameters of confined macromolecules. // Macromol. Theory Simul., 1999, vol. 8, p. 603-610.

8. Kuznetsov D., Balazs A.C. Phase behaviour of end-functionalized polymers confined between two surfaces. // J. Chem. Phys., 2000, vol. 113, p. 2479-2483. 
9. Sommer J.-U., Hoffmann A., Blumen A. Block copolymer films between neutral walls: A Monte Carlo study. // J. Chem. Phys., 1999, vol. 111, p. 3728-3732.

10. Sotta P., Lesne A., Victor J.M. The coil-globule transition for a polymer chain confined in a tube: a Monte Carlo simulation. // J. Chem. Phys., 2000, vol. 113, p. 6966-6973.

11. Pakula T. Computer simulation of polymers in thin layers. I. Polymer melt between neutral walls - static properties. // J. Chem. Phys., 1991, vol. 95, p. 4685-4690.

12. Yethiraj A. Monte Carlo simulation of confined semiflexible polymer melts. // J. Chem. Phys., 1994, vol. 101, p. 2480-2497.

13. Sikorski A., Romiszowski P. Motion of star-branched vs linear polymer: A Monte Carlo study. // J. Chem. Phys., 1996, vol. 104, p. 8703-8712.

14. Sikorski A. Monte Carlo study of the dynamics of star-branched polymers. // Macromol. Theory Simul., 1993, vol. 2, p. 309-318.

15. Romiszowski P., Sikorski A. Temperature dependence of properties of star-branched polymers: a computer simulation study. // J. Chem. Phys., 1998, vol. 109, p. 29122920.

16. Sikorski A. Monte Carlo study of the collapse transition of flexible and semiflexible star-branched polymers. // Polymer, 1993, vol. 34, p. 1271-1281.

\section{Температурна залежність деяких властивостей зірково-гіллястих полімерів в обмеженому просторі. Вивчення методом Монте Карло}

\section{П.Ромішовскі}

Кафедра хімії, університет м. Варшави, 02-093 Варшава, Польща

Отримано 30 серпня 2001 р.

За допомогою копм'ютерного моделювання досліджено зірково-гіллясті молекули з 3 -х ланцюгів у просторі між двома паралельними відштовхувальними стінками, розташованими на відстані $d$ одна від другої. Моделювання проводилося для ланцюгів на простій кубічній гратці. Ланцюги складалися з $N=49,100$ і 199 ланок. Якість розчинника під час моделювання регулювалася за допомогою зміни взаємодії між сегментами. Також змінювалася товщина шару між стінками. Результати свідчать про те, що відбувається перехід полімерний клубок-глобула. Температура переходу не залежить від обмеження простору. Однак, показники скейлінгу радіусу гірації чутливі до величини $d$.

Ключові слова: моделювання методом Монте Карло, обмежений простір, гіллясті полімери, перехід полімерний клубок-глобула

PACS: 02.70.Lq, 36.20.Ey, 61.25. Hq, 07.05.Tp 